\title{
RESEARCH PAPER \\ WASTEWATER USE IN URBAN AGRICULTURE: AN EXPOSURE AND RISK ASSESSMENT IN ACCRA, GHANA
}

\author{
P. Antwi-Agyei" and J. Ensink \\ Environmental Health Group, Faculty of Infectious and Tropical Diseases, \\ London School of Hygiene and Tropical Medicine, Keppel Street, WC1E 7HT, London, UK \\ *Corresponding author: Princekaagyei@gmail.com
}

\begin{abstract}
Wastewater use in urban agriculture is common as a result of rapid urbanisation and increasing competition for water. This study sought to assess critical exposures associated with the transmission of faecal pathogens among farmers and consumers of wastewater irrigated produce and to assess the adoption of the multiple-barrier approach advocated by the WHO guidelines to minimise health risks. From September 2012 to August 2013, 323 soil and irrigation water samples, and 501 raw produce and ready-to-eat salad samples were collected from fields, markets, and kitchens in Accra, Ghana. All samples were analysed for E. coli using standard procedures. In addition, 693 participants including farmers, vendors, and consumers were interviewed and observed. The results showed that irrigation water was significantly more contaminated than farm soil, though exposure to soil was found to pose the key risk to farmers due to hand-tomouth events (10 events/day). Over $80 \%$ of the produce samples were found contaminated with E. coli, with street food salad found to be the most contaminated (4.23 Log E. coli/g). Risk factors identified for produce contamination included farm soil, wastewater use, and poor food and environmental hygiene. Awareness of the source of irrigation water was low, but despite the high awareness of health risk, consumers did not prioritize health indicators when buying produce. The study recommends the promotion of interventions that would result in more direct benefits to producers and vendors, together with hygiene education/inspection, hygiene certification, and enforcement of food safety byelaws in order to protect health.
\end{abstract}

Keywords: Ghana, wastewater irrigation, produce, risk perceptions, multiple-barrier approach

\section{INTRODUCTION}

Although the full extent of disease burden attributable to food-borne diseases is largely unknown, food hygiene and food safety are major public health concerns. Food-borne diseases result not only from consuming food contami- nated with pathogens such as bacteria, viruses and parasites, but also chemicals or bio-toxins (Hird et al., 2009 and Scallan et al., 2011). The risk factors for produce contamination are diverse, and may include animal, human and environmental sources such as wastewater used 
for irrigation (WHO, 2006). To safeguard human health when wastewater is used in agriculture, the World Health Organisation (WHO) has developed guidelines for its safe use. The current guidelines are based on a Quantitative Microbial Risk Assessment (QMRA). The guidelines also recommend a multiple-barrier approach which prescribes health protection measures at different entry points along the food chain in order to protect consumers and farmers health (WHO, 2006). This study aimed to determine key exposures associated with the risk of faecal related disease transmission from wastewater to farmers. The study also sought to identify key risk factors associated with the microbial quality of produce and ready-to-eat salad along the food chain. Finally the study determined how farmers, vendors and consumers' awareness of health risks of produce irrigated by wastewater influence their purchase, and consumption of food prepared with hygiene practices.

\section{METHODS}

The study was conducted in Accra, the capital of Ghana with a population of 1.9 million (GSS, 2012). The study adopted a mixed method approach where a total of 693 participants were interviewed from October 2012 to December 2012 (dry season), and from June to August 2013 (wet season). Lettuce, soil and irrigation water samples were collected from three wastewater irrigated fields, while lettuce/ cabbage and prepared salad were collected from three central markets and 50 street vending stalls/restaurants respectively. All samples were processed for $E$. coli using the membrane filtration technique with BBL MI agar (Beckton Dickinson, Sparks, USA) (Oshiro, 2002). Each farmer and market vendor was observed for 3 hours from 7:00 hrs to 10:00 hrs using structured observation guide, while each street food vendor was observed from 18:00 hrs to 21:00 hrs. Farmers were observed on their farming activities including irrigation and manure application, while vendors were observed on where and how they displayed and stored their produce. Questionnaires dealt with sanitation and food hygiene practices, factors that influenced the purchase of produce or prepared salad, awareness of the source of irrigation water or produce, and whether this awareness influenced participants' buying of salad vegetables. Three focus group (6 participants per group) discussions were also held each with market vendors and farmers.

\section{Data analysis}

Data analysis was done using STATA 12 (StataCorp LP, College Station, USA). All E. coli concentrations were $\log _{10}$ transformed before statistical analysis was performed on both normally and non-normally distributed data. The Mann-Whitney and Kruskal-Wallis tests were used to test for the association of risk factors with street vended salad microbial quality, while one-way anova and two sample t-test were used to assess the effect of risk factors on produce quality at farms, markets and restaurants in the univariable analysis. Statistically significant differences between exposures and outcomes in the multiple regression model were measured at $5 \%$ significance level.

\section{RESULTS AND DISCUSSION}

\section{Farmers exposure to faecal contamination}

Eleven farming activities were observed during the 3 hours, though the majority of time (142 minutes $(79 \%)$ out of 180 minutes) was spent on five key activities (irrigation, forking, removing weeds, bed preparation and transplanting), with irrigation being the most common (Fig. 1). Within the 3-hour observation when farmers were working, $86 \%$ of the farmers were observed to have their hands come into contact with soil for an average time of 100 minutes, 93\% worked bare-foot for 145 minutes, while $63 \%$ had their feet and hands exposed to irrigation water for at least 88 minutes.

Farmers were also observed to have their hands come into contact with their mouths when undertaking the various farming activities, and the median hand-to-mouth events (contacts) was observed to be 10 per day. With regards to microbial quality of environmental samples, the 


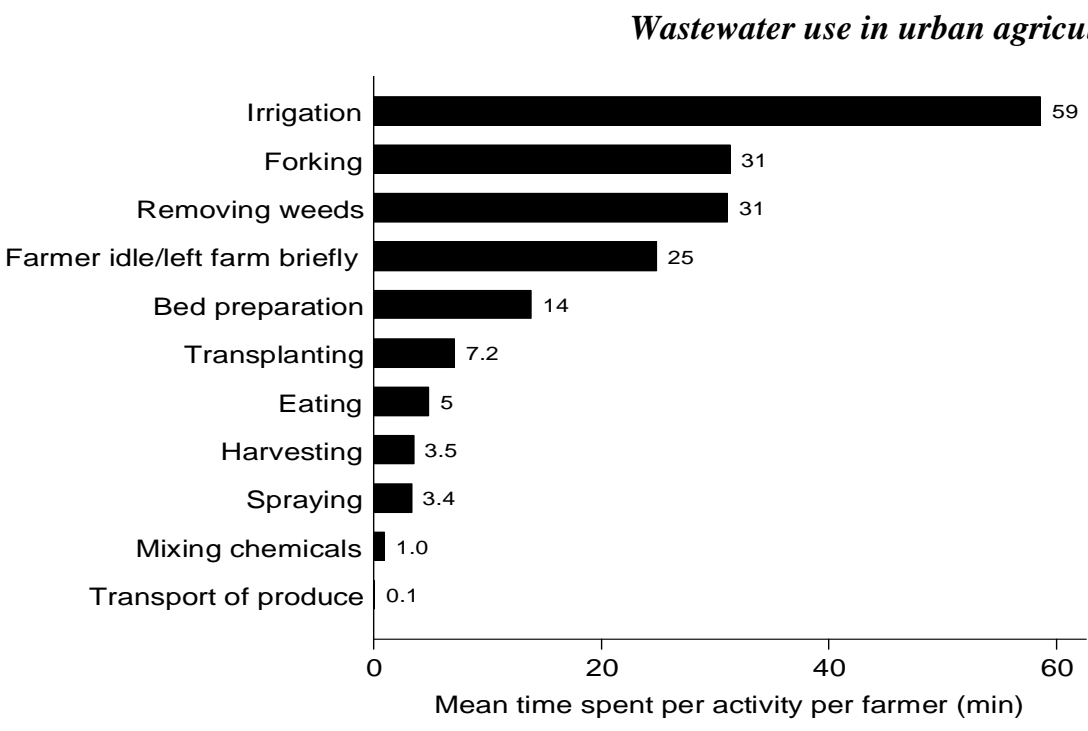

Fig. 1: Observed time (3 hours) for undertaking farm activities

median concentration of irrigation water was found to be $5.6 \log E$. coli/100 $\mathrm{ml}$, while the mean concentration of soil was $2.3 \mathrm{Log} E$. coli/ g. Despite the higher contamination of irrigation water, exposure to soil was found to be the key risk to farmers due to hand-to-mouth events, which were observed only during soil related activities. The findings on hand-tomouth contacts therefore support the WHO QMRA risk model approach that calculates permissible disease, or infection risk for farmers irrigating with wastewater based on the accidental ingestion of soil. This notwithstanding, farmers' exposure to wastewater could also be of significant risk when investigating pathogens, or chemical risks that occur via skin contact (Trang et al., 2007).

\section{Produce quality from farm to fork}

Out of the 501 produce and prepared salad samples that were collected, prepared salad from street food vendors was found to be the most contaminated (4.1 Log E. coli/g, p < 0.001, Fig. 2 ), and that only $10 \%$ of the samples had E. coli concentrations $<100 \mathrm{cfu} / \mathrm{g}$ and hence can be deemed satisfactory for consumption based on food safety standards (Ghana Standard Board (Authority), 2009). In addition, $40 \%$ of salad samples from restaurants, $12 \%$ of lettuce from wastewater fields, $20 \%$ of lettuce sold at markets, and $82 \%$ of cabbage from markets were also found to be satisfactory based on the Ghana food safety standards. The results of the study did not identify specific risk factors for street vended salad, though poor sanitation and hygiene practices at the vending sites could play a role (Fung et al., 2011), while the cut nature of the salad also facilitated the growth of microorganisms (Harris et al., 2003). Other risk factors for street salad could be the time between salad preparation and consumption, and vendors practice of not covering salad (Gil et al., 2009, Allende et al., 2008). A key recommendation for street food vendors will be to prepare salad in small quantities based on customer inflow, in order to prevent contamination due to inadequate storage and inappropriate temperatures. At restaurants, those who operated with a valid hygiene certificate had on average $1.53 \log E$. coli/g less contamination of their salad than those without hygiene permit, suggesting that local authorities should 


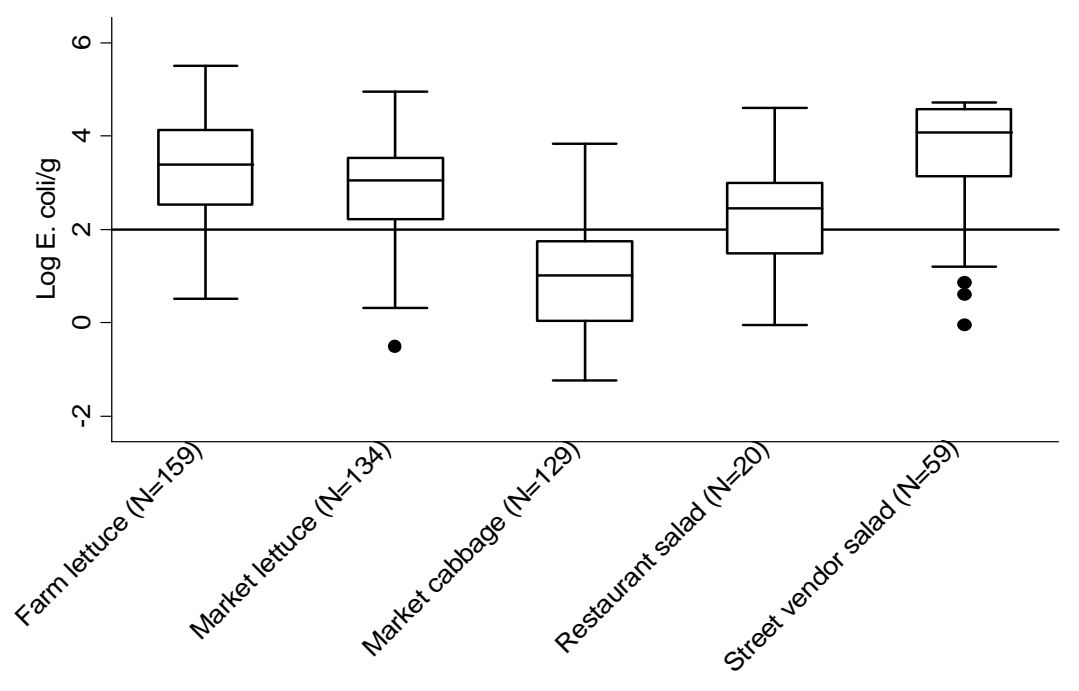

Fig. 2: $E$. coli concentrations in raw produce and ready-to-eat salad at different entry points along the food chain

Solid horizontal line: limit of E. coli concentration classified as microbiologically satisfactory for consumption

require vendors to obtain one.

No environmental exposures were identified at the markets that influenced market produce quality. However, the storage time of lettuce was associated with increased levels of $E$. coli on produce $(\mathrm{p}=0.05)$, while a $1^{\circ} \mathrm{C}$ increase in the storage temperature of cabbage also resulted in a reduction of $0.28 \mathrm{Log} E$. coli/g in the produce quality.

Vendors' washing practices at markets could also introduce microbial contaminants if the water was contaminated as was shown at markets in Portugal (Vaz da Costa Vargas et al., 1996) and in Bangladesh (Ali et al., 2012). Vendors are advised to wash produce under running potable water, or use multiple batches of potable water in order to prevent produce recontamination.

At farm level, the concentrations of E. coli found on produce increased with increased lev- els of $E$. coli found in soil or irrigation water. Although restrictions on the use of untreated wastewater, and adoption of crop restriction remain the best ways to ensure food safety in Accra, these measures are difficult to implement in resource constrained countries due to cost and lack of alternative sources of irrigation water. In such circumstances, interventions that require less restrictions and minimal financial investment are recommended, and should include controlled fetching of irrigation water from sedimentation ponds, and use of watering cans fitted with caps/filters for irrigation. (Keraita et al., 2008a and Keraita et al., 2008b).

Awareness of health risks and adoption of health protective measures

Awareness of the source of irrigation water used for vegetable cultivation was highest among market vendors (66\%), while a far lower proportion of street food consumers (30\%) claimed being aware of the sources of irrigation water (Fig. 3). Market vendors also claimed 


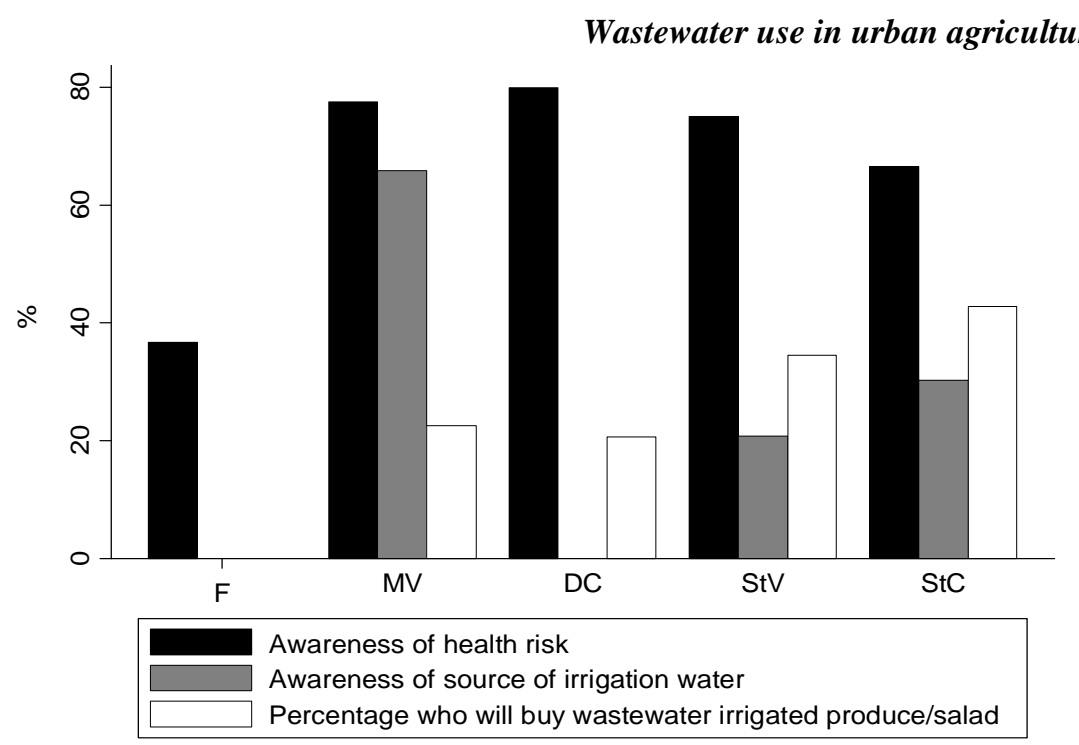

Fig. 3: Wastewater irrigation and health risk awareness and perceptions

$F=$ farmers, $M V=$ market vendors, $D C=$ domestic consumers (produce buyers at markets), $S t V=$ street food vendors, $S t C=$ street food consumers

good awareness of the origin of produce: "We know of the source of water farmers use to irrigate vegetables in Accra - you can even smell it when you buy the produce". At markets, less than half of domestic consumers (44\%) reported being aware of the source of produce they bought. Awareness of wastewater health risk was highest among domestic consumers $(80 \%)$ of produce and lowest among farmers $(37 \%)$. Knowledge of wastewater related diseases was also highest among domestic consumers with $66 \%$ correctly identifying diseases such as diarrhoea/cholera and worm infections. Although awareness of wastewater health risks was high among street food consumers, $35 \%$ of those who were aware of the health risks were unable to correctly mention a disease associated with exposure to wastewater. Street food consumers did not also prioritise health indicators when buying food. Only $2 \%$ of consumers chose a vendor based on food safety reasons with the majority concerned about the taste of the food (46\%, Fig. 4). Similarly, domestic consumers' choice of a vendor for produce was based primarily on friendship (28\%) and good price $(20 \%)$ and not on health indicators like clean environment. Consumers of street food also attributed the taste of the food $(49 \%)$ and convenience $(30 \%)$ as the main motivators for their consumption aside cost $(11 \%)$. For domestic consumers, buying produce was not influenced by awareness of health risk, or the source of produce, but was strongly associated with knowledge of the source of irrigation water $(\mathrm{OR}=8, \mathrm{p}<0.001)$. The fact that risk awareness, and knowledge of risks, do not necessarily translate into healthy behaviour has been shown in past hygiene programmes; with several studies having shown that knowledge of when to wash hands, did not translate in high hand washing rates at key times (Scott et al., 2007, and Freeman et al., 2014).

Our results also show that being aware of the health risk did not necessarily influence the buying of produce or consumption of salad particularly among domestic consumers. This finding could be due to the fact that most sales- 
12 Antwi-Agyei and Ensink

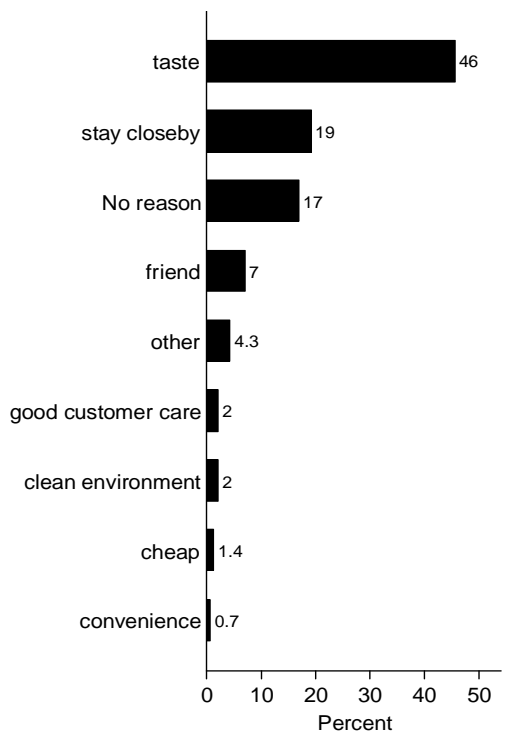

A

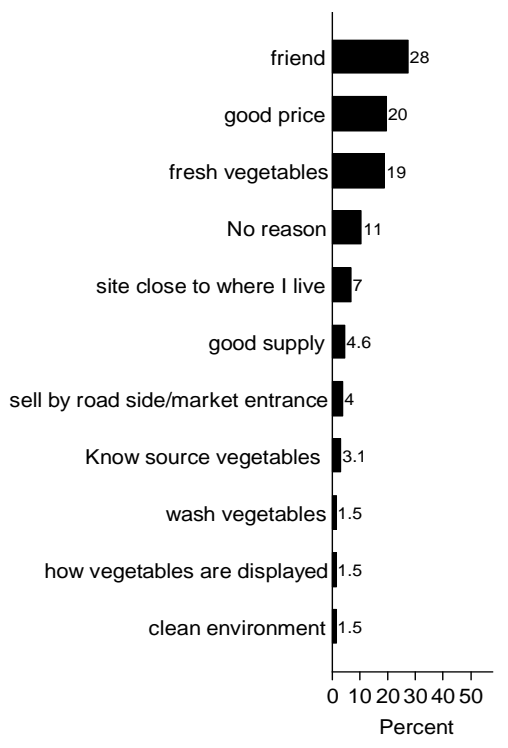

B

Fig. 4: Main factors influencing street food consumers (A) and domestic consumers (B) to buy prepared salad or produce from vendors $(\mathrm{N}=160 \mathrm{each})$

persons and consumers were unaware of the sources of produce, or the quality of irrigation water used for the produce. This is also likely to be true as the study results also confirmed that those who were aware of the source of produce and quality of irrigation water were less likely to buy wastewater irrigated produce. Convenience, or a lack of time is also an important driving force that makes consumers to buy produce at one particular place, or to use food vendors where the food quality is unknown. The findings of this study suggest that relying on health indicators to promote the adoption of health protective measures may not be sufficient to influence any behaviour change. An alternative approach would be to promote interventions that would create direct benefits to producers and vendors. These interventions may include the award of credit or loan schemes to farmers and vendors who abide by the prescribed risk reduction measures, support from agricultural extension officers on food hygiene, and development of communication channels to increase trust between vendors, local authorities, and consumers regarding food safety.

\section{CONCLUSION}

This study showed that there was potential health risk to wastewater irrigation farmers and consumers of wastewater irrigated produce, and hence the need to intervene appropriately to reduce these risks. Access to credit schemes and improved land security are recommended measures to encourage farmers to adopt risk reduction measures. Regarding health risk to consumers, risk reduction interventions should be prioritised at markets and kitchens, due to the high levels of contamination on produce/ salad at these sites, and the comparatively easier implementation of risk reduction measures at these domains compared to the farm level. Recommended measures include hygiene inspection and monitoring, hygiene certification and improved environmental and food hygiene practices. 


\section{REFERENCES}

Ali, M., Khan, M. and Saha, M. L. (2012). Antibiotic resistant patterns of bacterial isolates from ready-to-eat (RTE) street vended fresh vegetables and fruits in Dhaka City. Bangladesh Journal of Scientific Research, 24: 127134.

Allende, A., Selma, M. V., López-Gálvez, F., Villaescusa, R. and Gil, M. I. (2008). Role of commercial sanitizers and washing systems on epiphytic microorganisms and sensory quality of fresh-cut escarole and lettuce. Postharvest Biology and Technology, 49: 155 $-163$.

Freeman, M. C., Stocks, M. E., Cumming, O., Jeandron, A., Higgins, J., Wolf, J., PrüssUstün, A., Bonjour, S., Hunter, P. R. and Fewtrell, L. (2014). Systematic review: hygiene and health: systematic review of handwashing practices worldwide and update of health effects. Tropical Medicine \& International Health, 19: 906-916.

Fung, J., Keraita, B., Konradsen, F., Moe, C. and Akple, M. (2011). Microbiological quality of urban vended salad and its association with gastrointestinal diseases in Kumasi, Ghana. International Journal of Food Safety, Nutrition and Public Health, 4: 152-166.

Ghana Standard Board (Authority), G. (2009), Ghana Standard Board (GS 955:2009) Microbiological Analysis of Foods - Sampling Plans and Microbiological Criteria. ICS 0.7.100.30; 67.050.

Gil, M. I., Selma, M. V., López-Gálvez, F. and Allende, A. (2009). Fresh-cut product sanitation and wash water disinfection: problems and solutions. International Journal of food microbiology, 134: 37-45.

GSS (2012). 2010 Population and Housing census. Accra: Ghana Statistical Service.

Harris, L., Farber, J., Beuchat, L., Parish, M.,
Wastewater use in urban agriculture ... 13

Suslow, T., Garrett, E. and Busta, F. (2003). Outbreaks Associated with Fresh Produce: Incidence, Growth, and Survival of Pathogens in Fresh and Fresh-Cut Produce. Comprehensive Reviews in Food Science and Food Safety, 2: 78-141.

Hird, S., Stein, C., Kuchenmüller, T. and Green, R. (2009). Meeting report: second annual meeting of the World Health Organization initiative to estimate the global burden of foodborne diseases. International journal of Food Microbiology, 133: 210-212.

Keraita, B., Drechel, P. and Konradsen, F. (2008a). Using on-farm sedimentation ponds to improve microbial quality of irrigation water in urban vegetable farming in Ghana. Water Science \& Technology, 57: 519-525

Keraita, B., Drechsel, P., Konradsen, F. and Vreugdenhil, R. C. (2008b). Potential of simple filters to improve microbial quality of irrigation water used in urban vegetable farming in Ghana. Journal of Environmental Science and Health, Part A, 43: 749-755.

Oshiro, R. (2002). Method 1604: Total Coliforms and Escherichia coli in water by membrane filtration using a simultaneous detection technique (MI Medium). Washington, DC: US Environmental Protection Agency.

Scallan, E., Hoekstra, R. M., Angulo, F. J., Tauxe, R. V., Widdowson, M.-A., Roy, S. L., Jones, J. L. and Griffin, P. M. (2011). Foodborne illness acquired in the United States-major pathogens. Emerging infectious diseases, 17: 16-22

Scott, B. E., Lawson, D. W. and Curtis, V. (2007). Hard to handle: understanding mothers' handwashing behaviour in Ghana. Health Policy and Planning, 22, 216-224.

Trang, D. T., Van Der Hoek, W., Tuan, N. D., Cam, P. D., Viet, V. H., Luu, D. D., Konradsen, F. and Dalsgaard, A. (2007). Skin 


\section{Antwi-Agyei and Ensink}

disease among farmers using wastewater in rice cultivation in Nam Dinh, Vietnam. Tropical Medicine and International Health, 12: 51-58.

Vaz da Costa Vargas, S., Bastos, R. and Mara, D. (1996). Bacteriological aspects of wastewater irrigation. Tropical Public Health Engineering (TPHE) Research Monograph, 8.

WHO (2006). Guidelines for the safe use of wastewater, excreta and greywater: Wastewater use in agriculture (Volume II). Retrieved on 09/03/205 from persistent URL: $h t t p: / / w w w . w h o$. $i n t /$ water_sanitation_health/wastewater/ gsuweg2/en/index. html. 